\title{
Toxoplasma Gondii Infection in Risk Population Groups from Andes Peruvian
}

\author{
Jhosef Quispe Pari1,2, Ramirez Yauyo', Almidon Aquino', Mallqui Adauto', Salome Ochoa ${ }^{1,2}$, \\ Armida Rojas ${ }^{1,2}$, Raul Montalvo ${ }^{{ }^{*}}$
}

${ }^{1}$ Faculty of Human Medicine, "Universidad Nacional del Centro del Perú", Huancayo, Peru

2"Hospital Nacional Ramiro Prialé Prialé”, Huancayo, Peru

Email: ^otivo3@hotmail.com

How to cite this paper: Pari, J.Q., Yauyo, R., Aquino, A., Adauto, M., Ochoa, S., Rojas, A. and Montalvo, R. (2020) Toxoplasma Gondii Infection in Risk Population Groups from Andes Peruvian. Open Journal of Medical Microbiology, 10, 26-32. https://doi.org/10.4236/ojmm.2020.101003

Received: January 19, 2020

Accepted: March 1, 2020

Published: March 4, 2020

Copyright $\odot 2020$ by author(s) and Scientific Research Publishing Inc. This work is licensed under the Creative Commons Attribution International License (CC BY 4.0).

http://creativecommons.org/licenses/by/4.0/

\section{Open Access}

\begin{abstract}
Toxoplasmosis is a parasitic infection whose clinical presentations depend on the human's immune response. They can range from asymptomatic to rapidly progressive and deadly. There are no data on this disease in our population. Therefore, we have proposed to know the seroprevalence of toxoplasmosis in population risk groups through a descriptive, exploratory study in the 3 most populated districts of the province of Huancayo. The samples were processed by ELISA method and there were a total of 169 samples, 85 pregnant women and 84 cancer patients. The seroprevalence found in pregnant women was $44.7 \%$ and in cancer patients it was $26.2 \%$. Finally, the only risk factor associated with positive serology was the place of origin, having a higher risk for those living in the district of Huancayo and Chilca compared to El Tambo ( $\mathrm{p}$ $<0.05)$.
\end{abstract}

\section{Keywords}

Toxoplasmosis, Seroprevalence, Toxoplasma Gondii, Antibodies IgG

\section{Introduction}

Toxoplasmosis is a parasitic infection, which affects one third of the world's population [1]. This infection is usually asymptomatic except in risk groups such as: immunocompromised patients, pregnant women or newborns; who can present a very severe condition with permanent and even fatal sequelae.

The infection cycle begins with the ingestion of tissue cysts of toxoplasma by felines, which at the intestinal level develop their sexual cycle and then are released into the environment as oocysts by feces. The oocysts mature in the environment and are accidentally ingested by human or by animals for human con- 
sumption. Therefore, toxoplasma enters the human orally by contaminated food, undercooked meat or water. Once the human acquires the infection, it can be transmitted transplacentally or through transfusions [1].

There are 3 infectious stages of the parasite: the tachyzoites that are responsible for the clinical manifestations of the disease and its rapid multiplication, the bradyzoites that are the latent forms of the parasite and the sporozoites that are found within the oocysts and are released into the environment to continue the cycle of infection [2].

Geographically, Peru is divided into 3 regions: jungle, coast and mountains, being a seroprevalence of toxoplasmosis from $47 \%$ to $84 \%$ in the jungle, $42 \%$ to $44 \%$ on the coast and $0 \%$ to $44 \%$ in the mountains [3] [4]. Other studies, such as in blood bank units report seroprevalences of $84 \%$ for IgG and $4.9 \%$ for IgM [5], seroprevalences of $46.9 \%$ were also found in hospitals although these were with small populations [6].

Due to the severe presentations in immunocompromised patients, pregnant women and newborns and the limited information of toxoplasmosis in our population, it is necessary to know the seroprevalence and the main demographic characteristics of this infection, with the purpose of proposing prevention and early diagnosis strategies to reduce their probable complications.

\section{Materials and Method}

\subsection{Study Design}

The study was conducted in 03 of the 28 districts of the province of Huancayo, which covers $71 \%$ of its population (Huancayo, El Tambo and Chilca). The province of Huancayo is located in the department of Junín, located in the central highlands of Peru, at an altitude of 3250 meters, Huancayo has a population of 545,615 habitants: 119,$993 ; 91859$ and 166,359 persons belong to the district of Huancayo, Chilca and El Tambo respectively. $92.3 \%$ of its population is considered as urban population and have a coverage of water and drainage services of $94.2 \%$ and $61 \%$ respectively [7].

\subsection{Statistical Analysis}

An analytical observational study was conducted in the 03 most populated districts of the Province of Huancayo in the month of January 2019. Two study groups were selected: first trimester pregnant women and patients over 18 years of age with oncological diagnosis, to know the proportion of early infection and communicate the results to your treating physician and consider the possibility of treatment.

For the calculation of the sample and the statistical analysis, the STATA program was used, which averaged the seroprevalence found at national and local level. A seroprevalence average of $55 \%$ in the general population, $80 \%$ seroprevalence in pregnant women and $27 \%$ seroprevalence in cancer patients was taken [3] [8]; obtaining 85 pregnant women and 84 cancer patients. 


\subsection{Sample Collection}

For the sampling, authorization was requested from 06 Health Centers in the province of Huancayo. Once the patient was captured, the informed consent was signed and the questionnaire filled out, including data such as: age, sex, place of birth, place of residence, contact with cats, gestational age, type of cancer differentiated into three groups (solid, gastrointestinal and hematologic) and other probable risk factors. Regarding contact with cats, it was considered positive when the patient had cats as pets or there were cats in the neighborhood.

For the blood sampling, $3 \mathrm{cc}$ of venous blood was extracted in sterile bottles, which were immediately centrifuged and the serum was stored at a temperature of minus $70^{\circ} \mathrm{C}$ for further processing.

\subsection{Serological Analysis}

The serological analysis was performed in the microbiology laboratory of the Faculty of Medicine of the "Universidad Nacional del Centro del Perú". The serum was analyzed for antibody-toxoplasma IgM and IgG through the kit for toxoplasma IgG (NovaLisa immunodiagnostic GMBH, Dietzenbach, Germany) and the kit for toxoplasma IgM (NovaLisa immunodiagnostic GMBH, Dietzenbach, Germany). The test was performed according to the kit instructions. These kits have a sensitivity and specificity of the test above 95\% [9].

\subsection{Ethical Aspects}

Informed consent was obtained prior to the collection of patient data. This study was approved by the "Universidad Nacional del Centro del Perú" and the ethics committee of the Hospital "Daniel Alcides Carrión - Huancayo". In addition, the authors declare that they have maintained confidentiality in the handling of the information and the results obtained.

Regarding the positive results, these were given confidentially to the attending physician to assess their treatment.

\section{Results}

A total of 169 samples were analyzed, 85 were pregnant women and 84 cancer patients. Among the pregnant women, the average age was 29 years with $41.2 \%$ between 28 and 38 years, we also found that $44.7 \%$ (n: 38 ) were positive at least for an IgG or IgM marker and only $8.2 \%$ corresponded to positive results for IgM. When analyzing the place of origin, $61.2 \%$ came from the district of Chilca, but the averages of seropositivity by district were comparable. Regarding cancer patients, the average age was 59 years, $56 \%$ corresponded to women and the percentage of positive serology was $26.2 \%$ (Table 1 ).

By joining both groups and analyzing related factors, we found that $33.9 \%$ of those with a noble housing had positive serology for toxoplasmosis, $33.1 \%$ of those who had contact with cats had positive serology, $33.3 \%$ of those who consumed little meat cooked had positive serology and $37.5 \%$ of those who consumed 
Table 1. General characteristics according to risk group.

\begin{tabular}{|c|c|c|}
\hline Characteristic & $\begin{array}{c}\text { Pregnant } \\
\mathrm{n}=85(50.3 \%)\end{array}$ & $\begin{array}{c}\text { Cancer } \\
\mathrm{n}=84(49.7 \%)\end{array}$ \\
\hline Age: Average (rank) & $29(14-43)$ & $59(22-89)$ \\
\hline \multicolumn{3}{|l|}{$\operatorname{Age}^{*}$ n (\%) } \\
\hline$<28$ & $43(50.6 \%)$ & $1(1.2 \%)$ \\
\hline $28-38$ & $35(41.2 \%)$ & $6(7.1 \%)$ \\
\hline $39-59$ & $7(8.2 \%)$ & $35(41.7 \%)$ \\
\hline$>59$ & $0(0.0 \%)$ & $42(50 \%)$ \\
\hline Female n (\%) & $85(100 \%)$ & $47(56 \%)$ \\
\hline \multicolumn{3}{|l|}{ Type of housing } \\
\hline Rustic & $35(41.2 \%)$ & $10(11.9 \%)$ \\
\hline Cement & $50(58.8 \%)$ & $74(88.1 \%)$ \\
\hline Contact with cats & $59(69.4 \%)$ & $71(84.5 \%)$ \\
\hline \multicolumn{3}{|l|}{ Serology Result: } \\
\hline $\mathrm{Ig}^{\#}$ M Positive n (\%) & $7(8.2 \%)$ & $3(3.6 \%)$ \\
\hline $\operatorname{Ig}^{\#}$ G Positive n (\%) & $31(37.7 \%)$ & $19(23.8 \%)$ \\
\hline $\mathrm{Ig}^{\#}$ Positive Total & $38(44.7 \%)$ & $22(26.2 \%)$ \\
\hline \multicolumn{3}{|c|}{ Procedency } \\
\hline Huancayo & $17(20 \%)$ & $29(34.5 \%)$ \\
\hline El Tambo & $16(18.8 \%)$ & $49(58.3 \%)$ \\
\hline Chilca & $52(61.2 \%)$ & $6(7.1 \%)$ \\
\hline
\end{tabular}

${ }^{*}$ Age in years (quartiles). ${ }^{*}$ Inmunoglobulin (Ig).

raw water had positive serology. None of the factors evaluated previously had significance ( $p>0.05$ ). Finally, according to district of origin, it was found that living in the district of Tambo is a protective factor to have positive serology for toxoplasmosis, finding 2.8 and 3 times more risk of having positive serology if it comes from the district of Huancayo and Chilca respectively (Table 2).

\section{Discussion}

Toxoplasmosis is a disease caused by toxoplasma gondii that is an obligate intracellular parasite [2]. One of the most severe manifestations of toxoplasmosis is congenital toxoplasmosis, which mainly affects the eyes and central nervous system [10]. Its mechanism of transmission in pregnant women occurs in three ways: the first due to acute infection prior to conception; the second by reactivation in pregnancy due to some immunosuppression and the third by infection or reinfection of a more virulent strain during pregnancy [11] [12].

The SYROCOT study conducted in pregnant women showed that the probability of congenital toxoplasmosis increases with gestational age, while the probability of intracranial lesions decreases and ocular lesions do not depend on 
Table 2. Characteristics according to toxoplasmosis serology result.

\begin{tabular}{ccccc}
\hline Characteristic & $\begin{array}{c}\text { Analyzed } \\
\text { samples (n) }\end{array}$ & $\begin{array}{c}\text { Positive serology } \\
\mathbf{n}=60(35.5 \%)\end{array}$ & $\begin{array}{c}\text { Negative serology } \\
\mathbf{n}=109(64.5 \%)\end{array}$ & p value \\
\hline $\begin{array}{c}\text { Age: average (range) } \\
\text { Type of housing }\end{array}$ & 169 & $41(19-81)$ & $45(14-89)$ & 0.139 \\
Rustic & 169 & $18(30 \%)$ & $27(24.7 \%)$ & 0.472 \\
Cement & 169 & $42(70 \%)$ & $82(75.2 \%)$ & \\
Contact with cats & 85 & $8(21.1 \%)$ & $16(34.1 \%)$ & 0.230 \\
$\begin{array}{c}\text { Consumption of } \\
\text { undercooked meat }\end{array}$ & 85 & $9(23.7 \%)$ & $15(31.9 \%)$ & 0.402 \\
I consume raw water & 169 & & & 0.011 \\
District of origin & & $14(23.3 \%)$ & $51(46.79 \%)$ & \\
The tambo & & $20(33.3 \%)$ & $26(23.9 \%)$ & OR $(2.8)$ \\
Huancayo & & $26(43.3 \%)$ & $32(29.4 \%)$ & OR $(3.0)$ \\
\hline Chilca & & & & \\
\hline
\end{tabular}

gestational age. A limitation in our region specifically in Peru is that serial screening of our pregnant women is not carried out as if it was performed in said study. Therefore, knowing our regional prevalence in order to offer treatment to the population at risk is essential [13].

When evaluating the seroprevalence in the general population of Peru, we found that: in the jungle region, Iquitos in 2009, a seroprevalence of $97 \%$ IgG and $10 \%$ IgG and IgM was found for a studied population of 355 [14]. Similarly, in our capital, Lima, in 1997, Honorio Delgado hospital reported a seroprevalence of $14 \%$ [15]. These data demonstrate a large disparity in prevalence in our population.

Regarding pregnant women, a study conducted at the Lorena del Cuzco-Peru Hospital found a prevalence of $37 \%$ for a population of 90 pregnant women [16]. Meanwhile, in our study, we found a seroprevalence of $\operatorname{IgG}$ in pregnant women of $37.7 \%$. Assuming that the presence of IgG is a protective factor for congenital toxoplasmosis, we have about $62 \%$ of pregnant women at risk of developing toxoplasmosis during pregnancy.

While it is true it is difficult to specify that people are immunocompromised, in our study we wanted to know the seroprevalence of toxoplasmosis in cancer patients, in order to follow in future the clinical manifestations that this infection can produce. Of the cancer patients studied, we found a seroprevalence of 26.2\%. Globally, a meta-analysis with Chinese population that incorporated 19 studies showed a seroprevalence of $20.59 \%$ for the cancer population, compared to $6.31 \%$ for the population without cancer [17]. Other groups of researchers reported that people with ocular neoplasia had higher rates of toxoplasmosis [18]. In Turkey, IgG for Toxoplasma was detected in 63\% of cancer patients compared to $19 \%$ corresponding to the control group [19]. In Peru, no seropre- 
valence studies could be found in cancer patients.

When assessing risk factors, our study found a lower risk of having positive serology for toxoplasmosis in the population living in the Tambo district. No significance was found when evaluating contact with cats, consumption of raw water, consumption of undercooked meat or other factors evaluated. However, other studies did find these risk factors, so a study in northeast Ethiopia with HIV population and blood donors found sex, contact with cats and consumption of semi-rough meat as a significant risk [20]. Another similar study found that the consumption of unwashed fruits or vegetables is risk factors for toxoplasmosis [21].

Finally, it is necessary to conduct clinical studies to evaluate the impact of toxoplasmosis in our population since a high seroprevalence implies a greater risk of severe manifestations of this disease.

\section{Conflicts of Interest}

The authors declare no conflicts of interest regarding the publication of this paper.

\section{References}

[1] Dubey, J.P., Lindsay, D.S. and Speer, C.A. (1998) Structures of Toxoplasma gondii Tachyzoites, Bradyzoites, and Sporozoites and Biology and Development of Tissue Cysts. Clinical Microbiology Reviews, 11, 267-299. https://doi.org/10.1128/CMR.11.2.267

[2] Maldonado, Y.A. and Read, J.S. (2017) Diagnosis, Treatment, and Prevention of Congenital Toxoplasmosis in the United States. Pediatrics, 139, e20163860. https://doi.org/10.1542/peds.2016-3860

[3] Maguiña, C., Gotuzzo, E., Alvarez, H., Carcelen, A., Irrivaren, J. and Soto, J. (1998) Toxoplasmosis in Human Bartonellosis. Revista Medica Herediana, 9, 14-20. https://doi.org/10.20453/rmh.v9i1.564

[4] Cantella, R., Colichon, A., Lopez, L., Wu, C., Goldfarb, A., Cuadra, E., et al. (1974) Toxoplasmosis in Peru. Geographic Prevalence of Toxoplasma gondii Antibodies in Peru Studied by Indirect Fluorescent Antibody Technique. Tropical and Geographical Medicine, 26, 204-209.

[5] Fernandez, M. (2017) Seroprevalence of Toxoplasmosis in Blood Donors of the Tingo Maria Support Hospital. http://repositorio.unfv.edu.pe/bitstream/handle/UNFV/2247/FERNANDEZ\%20VA SQUEZ\%20MARILUZ\%20\%20CONSTANTINA.pdf?sequence=1\&isAllowed=y

[6] Cornejo Donayre, A., Cubas Nŭnez, E.O., Gonzălez, J.E., Pilares, R. and Năquira, F. (1971) Toxoplasmosis in Patients of the Hospital Obrero, Lima. Anales de la Facultad de Medicina, 54, 58-71. https://doi.org/10.15381/anales.v54i1.5020

[7] INEI: Cajamarca: Definitive Results of National Census 2017, Peru. https://www.inei.gob.pe/media/MenuRecursivo/publicaciones_digitales/Est/Lib157 $\underline{6 /}$

[8] Herrera, P. and Marcela, R. (1984) Seroepidemiological Study of the Prevalence of Toxoplasmosis in Inhabitants of the City of Lima. http://pesquisa.bvsalud.org/portal/resource/pt/lil-186983 
[9] Wilson, M., Remington, J.S., Clavet, C., Varney, G., Press, C. and Ware, D. (1997) Evaluation of Six Commercial Kits for Detection of Human Immunoglobulin $\mathrm{M}$ Antibodies to Toxoplasma gondii. The FDA Toxoplasmosis Ad Hoc Working Group. Journal of Clinical Microbiology, 35, 3112-3115. https://doi.org/10.1128/JCM.35.12.3112-3115.1997

[10] Breeze, A.C. (2007) Infectious Diseases of the Fetus and Newborn Infant, 6th edn. ADC Fetal and Neonatal Edition, 92, F156. https://doi.org/10.1136/adc.2006.102566

[11] Elbez-Rubinstein, A., Ajzenberg, D., Dardé, M.-L., Cohen, R., Dumètre, A., Year, H., et al. (2009) Congenital Toxoplasmosis and Reinfection during Pregnancy: Case Report, Strain Characterization, Experimental Model of Reinfection, and Review. The Journal of Infectious Diseases, 199, 280-285. https://doi.org/10.1086/595793

[12] Vogel, N., Kirisits, M., Michael, E., Bach, H., Hostetter, M., Boyer, K., et al. (1996) Congenital Toxoplasmosis Transmitted from an Immunologically Competent Mother Infected before Conception. Clinical Infectious Diseases, 23, 1055-1060. https://doi.org/10.1093/clinids/23.5.1055

[13] SYROCOT (Systematic Review on Congenital Toxoplasmosis) Study Group, Thiébaut, R., Leproust, S., Chêne, G. and Gilbert, R. (2007) Effectiveness of Prenatal Treatment for Congenital Toxoplasmosis: A Meta-Analysis of Individual Patients' Data. The Lancet, 369, 115-122. https://doi.org/10.1016/S0140-6736(07)60072-5

[14] Reategui, B. and Vela, G. (2011) Socioeconomic-Epidemiological Factors and Their Relationship with the Seroprevalence of Toxoplasmosis in Pregnant Women. Peruvian Association of Helminthology and Related Invertebrates (APHIA), 5, 31-40.

[15] Chavez, S. and Isable, M. (1997) Determination of G and M Immunoglobulin Titers in the Diagnosis of Toxoplasmosis. LILACS, 1.

[16] Cardenas, A. and Gloria, G. (1993) Seroepidemiological Study of Toxoplasmosis in Pregnant Women at Antonio Lorena Hospital. UNSSAC REPOSITORY.

[17] Jiang, C., Li, Z., Chen, P. and Chen, L. (2015) The Seroprevalence of Toxoplasma gondii in Chinese Population with Cancer. Medicine, 94, e2274. https://doi.org/10.1097/MD.0000000000002274

[18] Rai, S.K., Upadhyay, M.P. and Shrestha, H.G. (2003) Toxoplasma Infection in Selected Patients in Kathmandu, Nepal. Nepal Medical College Journal, 5, 89-91.

[19] Yazar, S. (2004) Investigation of Anti-Toxoplasma gondii Antibodies in Patients with Neoplasia. Journal of Medical Microbiology, 53, 1183-1186. https://doi.org/10.1099/jmm.0.45587-0

[20] Walle, F., Kebede, N., Tsegaye, A. and Kassa, T. (2013) Seroprevalence and Risk Factors for Toxoplasmosis in HIV Infected and Non-Infected Individuals in Bahir Dar, Northwest Ethiopia. Parasites \& Vectors, 6, Article No. 15. https://doi.org/10.1186/1756-3305-6-15

[21] Alzaheb, R.A. and Al-Amer, O. (2017) The Seroprevalence and Risk Factors of Toxoplasmosis among Female Undergraduate University Students in Saudi Arabia. Oman Medical Journal, 32, 486-491. https://doi.org/10.5001/omj.2017.93 